\title{
Definition of the initial information for selecting the cutting tool for automated production preparation
}

\author{
Aleksandr Golovko ${ }^{1, *}$, and Sergey Petrov ${ }^{1}$ \\ ${ }^{1}$ Kazan Federal University, pr.Syuyumbike, d.10A, Naberezhnye Chelny, 423812 ,Russian Federation
}

\begin{abstract}
The certain supply of cutting tools is formed on the machinebuilding enterprises of the parts group related to tooling as a result of application of technological processes. At preproduction of new pats group it is necessary to be determined with the choice of tool: to project special or to apply already present. In second case it is required to find from a database a suitable tool on totality of preset parameter. The large variety of constructions and methods of application of cutting tools hampers such choice. The article presents the initial information for selecting a cutting tool for automated production preparation.
\end{abstract}

The certain supply of cutting tools is formed on the machine-building enterprises of the parts group related to tooling as a result of application of technological processes [1-5].

At preproduction of new pats group it is necessary to be determined with the choice of tool: to project special or to apply already present [6-11]. In second case it is required to find from a database a suitable tool on totality of preset parameter [12]. The large variety of constructions and methods of application of cutting tools hampers such choice (Fig. 1).

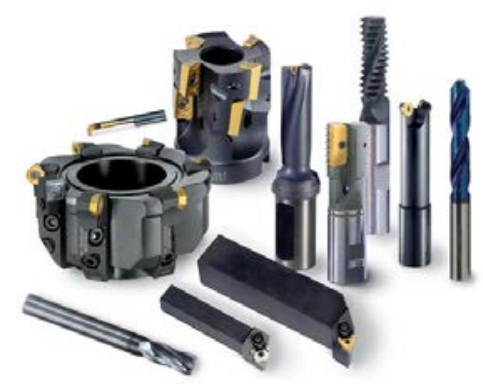

Fig. 1. Types of cutting tools.

In existent CASS of technological preproduction, on the stage of planning of technological process the choice of toolpiece, as a rule, performed in the conversational

\footnotetext{
* Corresponding author: a.n.gol@yandex.ru
} 
mode. The subsystem of choice of tools is absent usually, therefore this task decides by creation of different boolean functions. It results in their large variety, as in every case the set of basic data on composition is different. It also results in the increase of time of start of part group in a production, that results in additional financial losses. To eliminate the conversational mode of the system to the user it is necessary to be of expert of formalizing a choice tool by development and including of different boolean functions, that increases the volume of his work. It is caused by absence of satisfactory decision of the indicated tasks in existent CASS of technological preproduction. Planning is a process of search and processing of information. In most cases process is automated not enough, that causes the necessity of bringing in of user on the intermediate stages. As a result automation is taken to bringing in the forms of technological documentation of the information chosen in the conversational mode.

In an order to find out, what sort of information will be enough for the choice of tool we will consider his properties in a productive environment. These properties we will present as a chart reflecting the structural and technological signs of tool (Fig. 2).

Information characterizes an tool as part group showing the element of the technological system, and as means of tooling cutting. It will allow to carry out his search with an account, both possibilities of receipt of the required processed surface and options on a machine-tool with corresponding motions of executive mechanisms questioner the relative moving at primary forming.

The built chart allows to form a simple code from sixteen positions containing one of two possible values, that can be presented in a binary kind. The got code consists of sixteen bits broken on four groups, that is added to the existent base of tools as an additional attribute. Every position can set accordance certain information about a certain copy, for example, diameter of the tool bore, material of cutting part.

At planning of technological process to the moment of choice of tool the code of applicability is gradually formed.

For example, on the stage of planning of technological operation part of code of fourth group, on the stage of setting of machine-tool part of code of the second group. Further this code is used for a search in the base of these tools that can be applied for implementation of machining. As last can appear a few, then a final choice comes true in order of priority that is set by the third group of code.

It is possible to offer next priorities:

Providing of the required time of making, that is set by the modes of machining is material of cutting part.

Possibility of deployment is applicability.

A comfort of adjusting is possibility of subtuning.

A repairability is a method of renewal of parameters.

At a certain production the priorities can be proposed depending on their indexes of efficiency, for example, there can more priority be the use of tools with removable throwaway many-sided plates. For an example we will take the choice of tool for the lines of involute tooth the fourth group of code will look like 0011.At planning of operation and choice of machine-tool got, that an tool must be hard, to have an element of symmetry (axis of rotation) and collapsible construction. So the second group of code will look like 0111.

We it admits a database has :

- a gear cutter (1001.0011.0100.0011);

$$
\text { - a drill (1000.0010.0100.0000); }
$$

$\ldots$

- a worm milling cutter (1011.0111.0110.0011). 
A gear cutter and milling cutter befit on the fourth group of code, on the second group is a milling cutter.

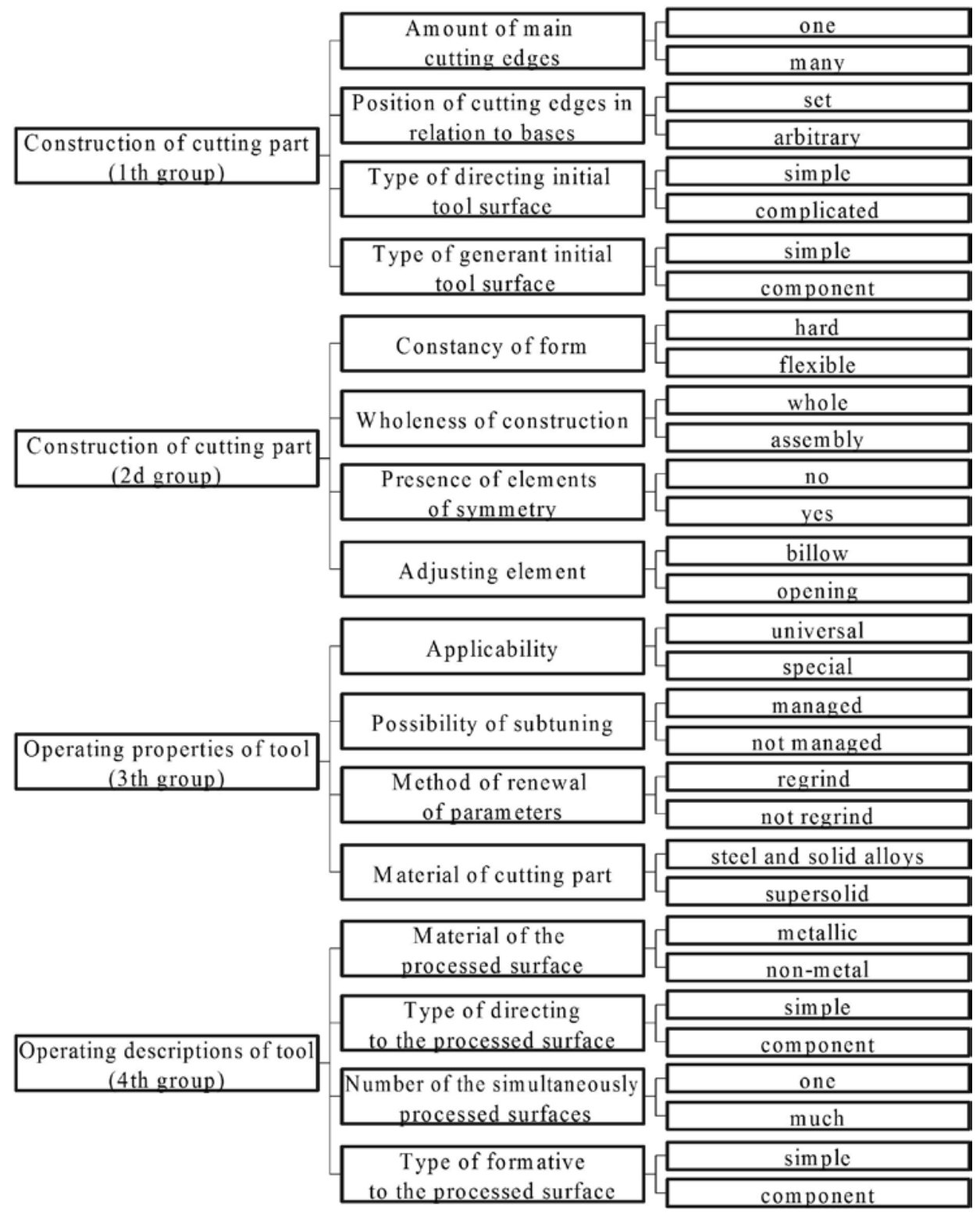

Fig. 2. Chart of structural and technological signs.

It is necessary to freeze a next step on the system of the instrumental providing of production, i.e. presence on storage, nomenclature of the bought in tools and delivery dates etc.

Coincidence all or parts of code, will allow to unite tools in classification groups. It will allow to undertake additional studies, for example, exposure of tools that can be excluded from the use on this production taking into account their interchangeability in the technological operations of machining. 


\section{References}

1. A.A. Matalin, Manufacturing engineering (Lan, St. Petersburg, 2010)

2. M.F. Pashkevich, Manufacturing engineering. Course and degree design (Grevtsov's publishing house, Minsk, 2010)

3. V.L. Kulygin, Manufacturing engineering (BASTET, Moscow, 2011)

4. O.V. Taratynov, Manufacturing engineering. Design bases on the computer (FORUM, Moscow, 2011)

5. I.S. Ivanov, Manufacturing engineering (INFRA-M, Moscow, 2012)

6. R.M. Khusainov, A.N. Golovko, S.M. Petrov, S.Y. Yurasov, I.P. Balabanov, V.A. Grechishnikov, V.B. Romanov, P.M. Pivkin, Selecting optimal cutting tools for lathes, Russian Engineering Research, v. 37(4), pp. 351-353 (2017)

7. R.M. Khusainov, S.Y. Yurasov, R.R. Kazargel'dinov, Preparations for production in unigraphics NX software, Russian Engineering Research, v. 37(4), pp. 363-366 (2017)

8. A.N. Golovko, I.V. Golovko, Kinematic calculation of the error in gear shaving, Russian Engineering Research, v. 31(10), pp. 1034-1035 (2011)

9. A. Golovko, Determination of the profile of the worm-type tool, MATEC Web of Conferences, 129,01043 (2017)

10. A.N. Golovko, A.G. Kondrashov, S.Yu. Yurasov, Improved design of a worm type instrument for final machining of evolvent gear teeth, Procedia Engineering, 206, pp. 1333-1336 (2017)

11. S.M. Petrov, G.K. Davletshina, B.F. Zairov, L.F. Zairov, Cutter profile of a mill for machining screw channels, Russian Engineering Research, v. 37(8), pp. 728-729 (2017)

12. S.V. Kasjanov, A.G. Kondrashov, D.T. Safarov, Regulation of geometrical parameters deviations of automotive components parts through diagnostic measurements organization, Procedia Engineering, 206, pp. 1508-1514 (2017) 